\title{
LA CHARITÉ hOSPITAL, PARIS.
}

Case Reported by M. J. halloran, aCting externe.

Very tight Traumatic Stricture of Urethra; Internal Urethrotomy with Maissonneuve's Instrument; Anuria until Death of Patient, Eighty-One Hours after the Operation. - On the 24th of July entered the service of M. Gosselin a patient, who, two months previously, had fallen on a board which struck directly against the perinæum. He experienced difficulty in urinating immediately afterwards, and the first water passed was bloody. From this moment he passed urine drop by drop; the day he entered very little escaped, and that contained pus in somewhat notable proportion. The patient had not had complete retention of urine. The following day (25th of July) M. Gosselin, after having attempted without success to pass a bougie with a bulbous end, tried every form of filiform bougie, first straight, then en baïonnette, that is, somewhat after the manner recommended by Brodie $;^{1}$ then he twisted the end of the bougie around a pin, so that it had an end somewhat like a corkscrew (bougie entortillee). This is a favorite form with M. Gosselin, and we have often seen him pass it when no other form would enter. He frequently recommends the device to his pupils; however, in this case it did not pass, and M. Gosselin not wishing to irritate the urethra too much did not pursue his attempts farther on that day. The day following, while attempting to insert the bougie, he injected oil into the urethra, but could not pass the stricture, which was extremely hard, almost gristly; from that time up to the 17th of August he tried patiently each day to pass the bougie, and during the last two days M. Berger, who was to take his place during the vacations, attempted also to enter, but without success.

The stricture appearing impermeable, the patient commencing to suffer during micturition, and the urine continuing purulent, M. Gosselin recommended to M. Berger, in departing, to perform external urethrotomy without a guiding staff.

A few days afterwards the patient succeeded in passing a very small filiform bougie, and the day following M. Berger passed the bougie No. 2, French scale (No. $\frac{1}{2}$ English) by its side, instructing the patient to urinate with both in the urethra (a favorite method with M. Gosselin and his pupil, M. Berger), to enlarge the stricture by the urine passing by the side of the two bougies.

The next day M. Berger withdrew one of the bougies, and fixed another to it which served to introduce the hollow guiding staff of Maissonneuve's urethrotome. On this he passed a middling-sized blade of the urethrotome, and divided the stricture from in front, cutting through it again in withdrawing the instrument. Then directly over the staff which had served to guide the cutting instrument M. Berger passed a No. 17 sound (No. $8 \frac{1}{2}$ English scale) with the end cut off. This sound entered readily, and was fixed in the urethra, the patient being directed to allow the urine to pass freely by it, and not to make the slightest effort in urinating. This introduction of a sound M. Gosselin considers as important to insure the success of the operation; in fourteen cases where he had passed no sound he observed ten times a distinct chill, while in twenty-one cases where he had passed a sound he had seen a chill

1 Vide Erichsen's Surg., 6th edition, page 726. 
in but six. ${ }^{1}$ In forty cases operated on by Maissonneuve, where he had retained a catheter after the operation, there was but one fatal case. The patient, in this case, passed urine freely at first, colored with blood, by the sound, until the evening, when he had a violent and distinct shiver, followed by complete anuria, and at midnight he had a second rigor. His temperature in the evening was $39^{\circ}$ Centigr., and the following day it mounted to $40^{\circ}$ Centigr. On the second day after the operation he commenced to vomit; the anuria was complete, and there was not a drop of urine in the bladder. He suffered much in the renal regions; the temperature fell; he was much depressed; his intelligence became obtuse; and he succumbed eighty-one hours after the operation. The treatment during this period of uræmia had consisted in dry cupping on the lumbar regions, sulphate of quinia grs. xiiss. ad grs. xx. daily, alcoholic stimulants, milk, etc.

Post-Mortem Examination. On the mucous coat of the floor of the urethra was found the trace of the incision made by the urethrotome, about an inch in length; a little farther back was a small urinary abscess opening into the canal. There were old coagulations in the periprostatic venous plexus. No pus in the veins. The traces of suppurative inflammation were found in the kidneys. The other organs were normal.

It may not be uninteresting to add to this observation, which needs no comment, and in which M. Verneuil considered that the patient had succumbed to nephritis provoked by the operation, the kidneys being previously diseased, and the patient dying in exactly the same manner as certain patients in albuminuria, a few statistics relative to the operation by Maissonneuve's instrument. First, that of Maissonneuve himself: In one hundred operations, seventy performed with uncovered sharp blade, and thirty with the lithotome cache with no sound after operation, he had eleven deaths from the operation, and six from other causes; of forty cases operated on with uncovered urethrotome with blunt blade, and in which he constantly retained the catheter after the operation, he had but one death. ${ }^{2}$ Gosselin, in thirty-five cases, operated on up to January 1, 1873, had lost but one, and in that the urine had passed during the operation. ${ }^{3}$ While Teevan, in thirty-five cases, operated on by the urethrotome of Maissonneuve, as modified by himself, has not had a single fatal case. ${ }^{4}$

Thus, though it has been said that " a scratch on the urethra is not without its dangers" (Gouley), this operation is not so hazardous as it has been generally considered. In four hundred and eleven cases of stricture it was performed but eleven times (Teevan). ${ }^{5}$ Yet it becomes a question whether it should not be performed in all cases where the stricture after several attempts at gradual dilatation proves refractory. A good example of the benefits sometimes resulting from this operation, the cure of a tight stricture which had caused several times perineal abscess and fistula, is the second case reported by M. Whitmore in the Lancet, December 27, 1877.

1 Leçons cliniques, vol. ii., page 228, 1st edition.

2 Year Book of Sydenham Society, 1863, page 313.

8 Leçons cliniques, vol. ii., page 227, 1st edition.

Lancet, vol. ii., 1877, page 829.

- Lancet, vol. ii., 1877, page 829. 